\title{
O LAZER E AS TRANSFORMAÇÕES SOCIOCULTURAIS CONTEMPORÂNEAS
}

\author{
Maria Dilma Simões Brasileiro \\ Universidade Federal da Paraíba, Brasil
}

\begin{abstract}
Resumo: Este ensaio tem como objetivo compreender as transformações socioculturais vividas na contemporaneidade, e como estas transformações influenciam e são influenciadas pelo trabalho, tempo livre e lazer. Remete para uma introdução na discussão sobre as mudanças de paradigma da modernidade para a pós-modernidade. Posteriormente, para situar esta análise no âmbito do lazer, realizamos um breve percurso na construção sociocultural do lazer, e como esses períodos históricos anteriores influenciam este conceito na contemporaneidade. Apontamos, portanto, para mudanças de paradigma da modernidade para a pós-modernidade, embora ainda não tenhamos condições de avaliar os caminhamos que poderão ser trilhamos por estas mudanças, já que ainda são imprecisas as categorias analíticas construídas para interpretá-las. Podemos sim afirmar que, as vivências humanas experimentadas a partir dos novos contornos socioculturais, favorecem o aparecimento de novos comunitarismos e individualismos, que estão redefinindo e sendo redefinidos, pelo que na contemporaneidade entendemos por trabalho, tempo livre e lazer.
\end{abstract}

Palavras-chave: Lazer; Trabalho; Tempo Livre; Modernidade; Pós-modernidade.

\section{Introdução}

Antes de iniciarmos uma aproximação ao conceito de lazer no contexto das transformações socioculturais, centramos nossas reflexões sobre o conceito de sociedade pós-moderna. Este conceito, na realidade, representa as transformações socioculturais vividas na contemporaneidade. É importante matizar que, dada a pluralidade de sentidos e definições usadas pelos autores para caracterizar estas transformações contemporâneas, neste ensaio não trataremos de aprofundá-las, senão refletir sobre a influência destas transformações no lazer e suas manifestações.

Ainda cabe destacar que analisaremos não só as influências destas transformações para o lazer, mas na reciprocidade e influência do lazer, na concretização destas transformações socioculturais. Portanto, para compreender esses processos vividos na contemporaneidade, convém iniciarmos analisando o significado e as transformações das sociedades modernas para as sociedades pós-modernas.

\section{Dos valores Modernos aos valores Pós-modernos}

Os valores da produtividade racionalista, a concepção positivista de mundo, as verdades estabelecidas que se inicia na Ilustração, nos séculos XVII e XVIII, começam a 
entrar em crise, mais acentuadamente a partir da segunda metade do século XX. Como analisa Lash (1997, p. 143):

o avanço da individualização na segunda fase, reflexiva, da modernidade, também liberou os indivíduos das estruturas coletivas e abstratas, tais como a classe, a nação, a família nuclear e a crença incondicional à ciência.

A modernidade, definida pela destruição das estruturas antigas, pelo triunfo da racionalidade e pelo rompimento do mundo sagrado, que era tanto natural como divino, perde força e entra em declínio. $\mathrm{Na}$ contemporaneidade, estamos vivendo em uma sociedade industrial/moderna, centrada na produção em série de bens materiais, mas convivendo também com uma sociedade pós-industrial/pós-moderna, centrada na produção de meios não materiais (informações, símbolos, estética, valores etc.). Nas análises de De Masi (2000), as mudanças vividas nas sociedades, com o passar da história, estão cada vez mais curtas. Quinhentos anos foram necessários para a organização da sociedade moderna e industrial; apenas duzentos anos do processo de industrialização foram suficientes para provocar o advento da sociedade pós-industrial.

Depois do período rural e do período mais breve do maquinismo industrial, apresentase na atualidade um terceiro período, o pós-industrial, capaz de exaltar a dimensão criativa das atividades humanas, privilegiando mais a cultura que a estrutura. Se a modernidade, com base na razão, foi capaz de criar o Estado de direito e o mercado, o mesmo não podemos afirmar em relação à liberdade e à felicidade. Como analisa Touraine (2009), a ideia de que o progresso seria o caminho para o desenvolvimento, a liberdade e a felicidade, está cristalizada na figura do masculino ocidental, adulto e educado, que defende uma empresa, uma nação e/ou sociedade e que domina os trabalhadores, colonizados, as mulheres e crianças. Entretanto, os fatos históricos têm demonstrado que esta autoridade racional legal, centrada nesta concepção ocidental de mundo, do homem de Estado e do capitalista, não foi suficiente para o triunfo da modernidade.

Na verdade, analisar este processo da modernidade para a pós-modernidade é sugerir, como ressalta Featherstone (2000, p. 24), "uma mudança ou ruptura de época com a modernidade, que trás o aparecimento de uma nova totalidade social, com seus princípios distintos de organização”. Neste contexto, a ciência, a tecnologia, a globalização, o progresso organizativo, a escolarização e os meios de comunicação de massa, foram elementos determinantes para impulsionar a dinâmica da nova sociedade pós-moderna. Para Eagleton (1998, p. 11), 
a pós-modernidade é um estilo de pensamento que desconfia das noções clássicas de verdade, razão, objetividade, da ideia de progresso universal ou da emancipação das estruturas isoladas, dos grandes relatos ou dos sistemas definitivos de explicação.

Nesta mesma linha de argumentação, Martín Horcajo (2003) entende a pósmodernidade como um estado de consciência que coloca limites aos sonhos de grandeza da modernidade, representados na razão científica. Aquela razão, que organiza nosso entendimento objetivo do mundo, que nos proporciona uma forma de vida desejada e que nos faz crê que sua evolução irá superar as injustiças sociais.

O próprio conceito de pós-modernidade, entretanto, não é unívoco, nem está salvo de orientações valorativas. Isto se comprova no extenso debate que existe sobre este conceito e as críticas que se fazem a ele. Assim, pois, desde o nosso ponto de vista, o que consideramos como pós-modernidade, muitos outros autores denominam como modernidade alta, modernidade tardia, hiper ou meta modernidade, modernidade reflexiva etc. Na realidade, uma gama de conceitos para interpretar as transformações sociais e culturais que se estão produzindo nas sociedades contemporâneas. Para Lyotard (1984), um dos percussores do conceito de pós-modernidade, as sociedades entram na idade chamada sociedade pós-industrial e as culturas entram na idade chamada pós-moderna. Este autor indica que a pós-modernidade se caracteriza por uma crise no conhecimento causada pelo ceticismo, relacionada às reinvindicações das verdades estabelecidas na modernidade.

Produz-se, portanto, um sentimento de inquietação nas categorias estabelecidas e nas ações associadas à modernidade. Featherstone (2000) ressalta que ainda não se tem elaborada teoricamente, em forma detalhada, a correspondente delimitação dos processos socioculturais e transformações institucionais derivadas deste período, "só contamos com a possibilidade de entender o conceito de pós-modernidade, a uma nova ordem social e a uma mudança de época” (Featherstone, 2000, p.28). Deriva-se assim, um processo cujas bases apresentam-se com maiores contornos nos anos 50, que culmina com a globalização das economias mundiais (as grandes empresas transnacionais, a divisão internacional do trabalho etc.); com um maior número de postos de trabalho no setor serviços; com as novas tecnologias, principalmente da informação; com o declínio dos meta-relatos; com a extensão da democracia como forma de governo; com a revolução cultural do lazer, em que o conhecimento simbólico compartilha o cenário com a produção dos bens materiais. Na análise de De Masi (1999), as mudanças neste período ainda não estão difundidas e radicadas, mas já se sente sua presença no mercado de trabalho, quanto o setor terciário começa a 
predominar em relação à agricultura e à indústria e na formação do produto interno dos países, em que prevalece os serviços sobre a produção dos bens materiais. Estas mudanças também estão presentes no sistema social, na produção do conhecimento teórico, da ciência e da informação, que agora ocupam papel central. Apontamos ainda para mudanças no sistema cultural, em que o individualismo e novos comunitarismos adquirem vigor crescente.

As transformações socioculturais se tornam ainda mais presentes no final da década de 60 e início dos anos 70. A instabilidade dos mercados, principalmente depois da crise de 1973, colabora para que o modelo de produção capitalista vigente entre em crise e "lança o mundo capitalista numa longa e profunda recessão, que muda a relação do Estado com as economias de mercado" (Brasileiro, 2012, p. 82), influenciando desta forma, nas relações socioeconômicas e culturais. Esta crise coloca em evidência as cargas tributárias para o setor social, produzindo uma reação liberal, privatizadora deste setor. Neste contexto, transformam-se as relações de trabalho, reforçando uma economia dominada pelo trabalho flexível e urbano. Como consequência, acontecem mudanças profundas e progressivas na Sociedade de Bem-estar. A sociedade civil organizada e os cidadãos individuais assumem cada vez mais protagonismo, e muitas das reivindicações e algumas funções que antes eram do Estado são assumidas e representadas por esses novos agentes sociais. Neste sentido, se algo se pode reconhecer na pós-modernidade, é uma mudança essencial na relação indivíduo/sociedade, já que nossa condição essencial de cidadãos, além de ativa, não mais somente representativa, agora é compaginada com nossa situação de consumidores, que exige novas posturas e organizações perante o Estado e o mercado. A descrença nos grandes projetos políticos e nas instituições, principalmente as públicas, conduz também os cidadãos à assumirem um novo protagonismo, tanto em relação a sua vida privada, aos problemas sociais, como na perspectiva e nos valores do mundo.

$\mathrm{Na}$ verdade, no mundo sociocultural, o ser humano que, no início da sociedade moderna ficava sem apoio diante da interpretação da Bíblia, fica agora, na sociedade pós-moderna, sem apoio da sociedade patriarcal e do Estado.

Depois de Deus absconditus, que desencadeou a confiança moderna nos poderes da espécie humana, chegou a Societas absconditus, que disparou a confiança pósmoderna nos poderes dos indivíduos. (Baumann e Tester, 2002, p. 123).

Neste sentido, a desintegração crescente do modelo social em sua forma clássica, tem provocado a busca de si mesmo e o sentido da vida. O indivíduo pós-moderno, que 
assume protagonismo crescente e ativo nas questões socioeconômicas, políticas e culturais, o indivíduo/cidadão/consumidor, também é o mesmo indivíduo que se assume como um estranho no mundo. Nas palavras de Rago (2000, p. 09),

o homem público do passado agora se converte em espectador silencioso do presente, figura indiferente, sem expressão física, facial e emocional, exposto no mundo das aparências. (...) Nos parques e praças, os óculos de sol reafirmam a busca do anonimato, enquanto o walkman garante a certeza de não se ouvir nada, fora o escolhido.

O espaço e tempo pós-moderno podem ser construídos de acordo com nossa individualidade, na medida em que temos que escolher entre as múltiplas opções que nos oferece a vida, adaptando-a e vivenciando-a de acordo com nossa situação pessoal. Em outras palavras, a pós-modernidade se traduz em uma sociedade plural e individual, em que o absoluto passa a ser relativo. Encontramo-nos, pois, em uma realidade múltipla e interconectada, sendo muito difícil dar conta isolada de qualquer faceta desta realidade, sem uma referência entre o individual/social; o local/global; o moderno/pós-moderno. Não existe um quadro da vida social que escape a esta realidade. Pode variar a intensidade, mas as transformações vividas na contemporaneidade abarcam todas as sociedades, em diferentes contextos do mundo. Portanto, o incremento dos valores pós-modernos é um dos elementos mais destacados no cotidiano das pessoas, constituindo também um fator determinante para se compreender as transformações no mundo do lazer.

\section{O lazer no contexto das transformações socioculturais}

O conceito de lazer, tal como entendemos e vivenciamos na contemporaneidade, iniciase com a sociedade moderna. Como analisa Elias (1992, p. 120), "de acordo com a estrutura diferente da sociedade grega, o conceito de lazer não possuía exatamente o mesmo sentido do nosso". Entretanto, sempre nas sociedades antigas teve algo equivalente ao que hoje chamamos de lazer, pois, paralelamente as atividades de sobrevivência, os indivíduos sempre desenvolveram atividades de representação e de experiências de si mesmo e da própria vida (Gaya, 1997).

Para os gregos, o que na atualidade se aproxima ao que chamamos de lazer, estava relacionado com a instrução, e consistia em se dedicar às atividades intelectuais que enriqueciam o espírito. Baseava-se na idealização de se encontrar, não só pré-disposto, mas principalmente disposto, para a contemplação dos supremos valores deste mundo: a verdade, a bondade e a beleza, ou seja, a sabedoria frente às atividades manuais. Os gregos consideravam o lazer como uma via de saber não utilitária, mas contemplativa, 
que se opunha à ocupação, em especial quando esta implicava em alguma atividade regida por objetivos concretos e utilitários. A finalidade do lazer residia em si mesmo, não podendo haver outra razão para realizar uma atividade de lazer que não fosse o mero fato de realizá-la. "Somente aquele que podia dispor de lazer era livre” (Mazón, 2001, p. 54). Evidentemente este lazer dos gregos, só era possível porque o trabalho estava assegurado pelos escravos (Russell, 2002). A estrutura democrática grega se encontrava delineada por uma sociedade de cidadãos livres, em que o lazer era para eles um espaço de desfrute, de aproveitamento da vida. Era um estado de paz interior e contemplação criadora. O lazer era para os homens instruídos na liberdade. Estes se distinguiam daqueles homens que eram educados na escravidão. Como explica López de la Vieja (1998), Aristóteles fazia elogio ao clássico lazer, firmemente assentado em condições desiguais. Para este filósofo, citado por López de la Vieja (1998, p. 18),

a ocupação da mente é superior às outras atividades, por encima da atividade militar ou da política. Entretanto, a contemplação não é produção, também não é ação, por isto só é possível, na ausência de cansaço. Viver desta maneira requer recursos dignos e também um uso moderado destes.

Aristóteles considerava que as atividades que cumpriam as características de lazer, ou seja, que implicavam uma formação humana não utilitária, era a contemplação e o ensino da música, por meio das habilidades de tocar, recitar e compor. Para este filósofo, isto tudo contribuía para formar a mente, possuir a cultura própria dos homens educados e aproximar-se das virtudes (Puig Rovira e Trilla, 1996). Encontrase, pois, nesta cultura, uma valorização das vivências que hoje se aproximam ao lazer e um desprezo às atividades que se relacionavam ao trabalho. Analisando esta situação, Heródoto, citado por Lafargue (1991, 67), se questionava sobre a origem destes valores, mas Heródoto concluía que não ele podia afirmar "se os gregos herdaram dos egípcios o seu desprezo pelo trabalho, porque encontro o mesmo desprezo estabelecido entre os trácios, os citas, os persas e os lídios". O próprio Lafargue $(1991,68)$ afirmava que "os filósofos gregos disputavam quanto à origem das ideias, mas estavam de acordo quando se tratava de odiar o trabalho". Nesta mesma direção, Veblen (2004), ao analisar as classes ociosas ao longo da história da humanidade e ao referir-se às comunidades bárbaras, o autor analisava que

a distinção entre proeza e trabalho ordinário é uma distinção de desigualdade degradante que se estabelece entre ocupações. Aquelas ocupações que se classificam como proezas são dignas, honradas, notáveis; as outras ocupações que não contém este elemento de proeza, e especialmente aquelas que implicam servidão e submissão, são indignas, degradantes e não nobres (Veblen, 2004, 41). 
A concepção grega do lazer, como contemplação e cultivo do espírito, não foi vivenciada em Roma, com a ascensão do Império Romano, pois esta sociedade apresentava novas conotações, que respondiam a outro contexto econômico e político, embora o valor ao lazer continuasse presente na classe dominante. Os clássicos autores gregos, como, por exemplo, Aristóteles, que inaugurou uma postura positiva ante o que hoje conhecemos como lazer, pode encontrar alguns seguidores como Séneca. Entretanto, tanto a organização da vida social, como a obra de outros autores contribuiu para cristalizar outra concepção de lazer neste período histórico.

Na cultura romana cabe distinguir, pois, entre o lazer da classe dominante, das elites, que se aproximava ao ideal do lazer grego, e o lazer do povo, associado ao divertimento. Roma introduziu o lazer das massas, por meio dos mimos e das comédias, que era organizado pelo próprio Estado. Este tipo de lazer, pensado para o povo, colaborava também para o domínio dos mesmos. Os dias de festa ocupavam quase a metade do calendário laboral e eram destinados, fundamentalmente, à diversão (Montaner, 1996; Puig Roviara e Trilla, 1996; Mazón, 2001). Desta forma, o lazer em Roma se realizava de acordo com os princípios gregos para a intelectualidade e as classes dominantes e o lazer como repouso e, sobretudo, como diversão, era para o povo, a massa. Como ressalta San Martín (1997), o conceito do lazer romano estava bem diferenciado entre a elite e o povo; para a elite, o lazer era recreio, meditação, descanso, vida social; por outro lado, o lazer do povo consistia num lazer das massas, panis et circenses, despreciado pela elite social. Neste caso, o lazer era fundamentalmente entretenimento e um instrumento político de dominação.

Com a queda do Império Romano, nasce uma nova organização social: a sociedade rural caracterizada pelo feudalismo, o local e o camponês. Desde o pensamento aristotélico, as atividades que promoviam o prazer já eram valorizadas. Entretanto, apesar do pensamento europeu ter absorvido, por meio da igreja cristã, o pensamento aristotélico, o prazer, promovido por elementos hedonistas do entusiasmo, da excitação produzida pela música, o drama, os jogos etc., foram suprimidos. O lazer do povo continua sendo basicamente um tempo de repouso e de festa, organizada e controlada pela Igreja Católica e os senhores feudais, que governavam a vida do povo e ditavam as concepções e valores da sociedade. O trabalho era compaginado com as atividades religiosas, e o lazer se misturava com as festividades religiosas, gerando, muitas vezes, festas pagãs e fora das normas da Igreja.

As festas e diversões eram momentos de ritos e convivência entre os membros da comunidade. Era um tipo de sociedade com um grande número de festas anuais. Como ressalva Ruiz Olabuénaga (1994, p. 1927), na Espanha medieval, “o Concílio de 
Calahorra estabelecia 45 'festas de guardar', as quais, somadas aos 53 domingos, completavam um calendário de celebrações cíclicas coletivas de quase cem dias atuais”. Lafargue (1991, p. 40) também faz referência aos feriados no Antigo Regime, em que "as leis da Igreja garantiam ao trabalhador 90 dias de descanso, 52 domingos e 38 dias feriados, durante os quais era estritamente proibido trabalhar". Com o avance da Idade Média, o tipo de lazer que se vai estruturando é totalmente da elite. Na verdade, os valores da elite neste período não consistiam somente na abstenção ao trabalho, mas também na dedicação as atividades de guerra e ao esporte e, em outro nível, à política, ciência e religião. Para a elite do período medieval, o lazer se exibe como ostentação, pois desperta respeito social, já que demonstra riqueza e, por consequência, poder (Montaner, 1996). A ideia grega de contemplação, sem desaparecer totalmente, vai perdendo espaço durante a Idade Média, embora na Renascença, retorne uma valorização a um prazer mental e a liberdade na arte.

A mudança gradual em direção a um conhecimento mais utilitário e prático se inicia no século XVII e transcorre o século XVIII, acelerada pela Revolução Francesa e pela industrialização. Deste período em diante, encontramos em processo uma concepção quase que oposta aos valores antecedentes relacionados ao lazer e ao trabalho, que guiará o ser humano ocidental até aos nossos dias. Apresenta-se, portanto, uma nova ideia de trabalho como expressão máxima do ser humano, da confiança em si mesmo e sua exuberante omnipotência (Puig Roviara e Trilla, 1996). O desenvolvimento da técnica e as mudanças na estrutura da sociedade feudal introduziram outros modos de produção. O trabalho gradativamente já não acontece no campo. As fábricas começam a ser o centro por excelência do trabalho e a dinâmica do cotidiano dos indivíduos se vê alterada, tanto espacial como temporalmente. A Reforma também traz consigo um novo significado para o que até então se aproximava ao lazer.

Com esta nova realidade, gera novos valores e assim reciprocamente. O lazer filosófico já não corresponde a uma forma de viver, assentada sobre a escravidão e oposta a desvalorização do trabalho. Desde então, cada um deverá procurar os meios para sobreviver por meio do trabalho, o qual se converte no caminho para a salvação. $O$ puritanismo inglês do século XVI, amparado nas doutrinas calvinistas, confere um valor ético e, inclusive, religioso ao trabalho, defendendo o lazer como ausência deste. Neste período, com os valores da Reforma, o trabalho é sinônimo de dignidade. A vida fica submetida à racionalidade e a valores nos quais o lazer não estava incluído. O lazer era improdutivo e tinha efeitos perversos, já que estimulava valores que não eram compatíveis com o trabalho. Tudo que estava relacionado ao prazer era condenado. $\mathrm{O}$ imperativo desta sociedade era trabalhar. Neste contexto, a função principal e bem- 
vinda do lazer era descansar, para repor as energias para voltar ao trabalho. Entramos na modernidade e nos valores modernos do lazer.

\section{O lazer, a modernidade e seus valores}

Na Inglaterra dos séculos XVI e XVII - e posteriormente nas colônias americanas - a inatividade era o pior dos vícios, pois significava a falta de esforço e, sem ele, não se podia conseguir a salvação na outra vida (Montaner, 1996). Como consequência dessas novas ideias e as novas condições sociais, o ritmo de trabalho dos indivíduos tendeu a ser cada vez mais duro. As horas de trabalho não baixavam nunca das 12 horas e, com frequência, chegavam a 16 horas. Os indivíduos já não associavam as horas de trabalho aos estritos horários solar da Idade Média. Até a revolução industrial, o sentido desta polarização entre o trabalho e as vivências do lazer não era evidente. Isto quer dizer que com anterioridade a revolução industrial, entre trabalho e tempo livre/lazer não havia uma enfrentamento explícito, senão uma relação de continuo e de equilíbrio mútuo. A vida das pessoas tinha um caráter unitário, embora nem por isto, era menos dura e penosa do que no início da modernidade e contemporaneidade, senão todo o contrário (Puig Rovira e Trilla, 1996). Esta mudança de paradigma do trabalho foi analisada por Lafargue (1991), no ano de 1883. Nas análises deste autor

A moral capitalista, lastimável paródia da moral cristã, lança um anátema sobre a carne do trabalhador: o seu ideal é reduzir o produtor ao mínimo de necessidades, suprimir as suas alegrias e paixões e condená-lo ao papel de máquina que produz trabalho sem trégua nem piedade (Lafargue, 1991, p. 09).

No início da revolução industrial, a realidade social era, portanto, o trabalho incessante do povo, compaginado com o lazer de uma classe ociosa (Veblen, 2004). Os burgueses, como máximos expoentes da moral do esforço, dedicavam sua vida aos negócios e aos lazeres instrutivos, que conservará as práticas do lazer ostentativo. Isto porque, a parte de possuir bens e poder, era necessária apresentar em público a distinção da classe social à qual pertencia. As atividades de lazer apresentam-se como um bom símbolo para esta distinção. A postura clássica do lazer filosófico já não estava tão em voga. Entretanto, o papel discriminador do lazer é mostrado pelos ricos, que tinham a exclusiva do lazer e o utilizava, já não para filosofar ou descobrir o sentido da vida, mas para distinguir-se dos demais, por meio de um estilo de vida específico. Portanto, assim como nos períodos anteriores, a classe ociosa, privilegiada, que cultiva os prazeres do lazer sempre existiu, porém assentada no trabalho dos escravos, camponês ou, na modernidade, dos operários. 
A ideologia puritana, que havia penetrado profundamente na classe burguesa, se entendeu principalmente durante os séculos XVIII e XIX. É com a Revolução Francesa que se produz também as últimas transformações, configurando o trabalho e o lazer modernos. Mas é com a consolidação do capitalismo que se construirá na sua plenitude o sentido moderno do trabalho, tempo livre e lazer. Com esta consolidação do sistema econômico, se consolida também a sociedade moderna, com uma perspectiva de que o lazer já não é mais o ideal grego, mas também não possui o caráter gratuito. No mundo industrial e moderno, a utilidade e os valores morais instituídos ao conceito de lazer são sinônimos de improdutividade e vagabundagem. O trabalho, este sim, "seria um freio para as nobres paixões do homem" (Lafargue, 1991, p. 24).

Neste contexto, o modelo clássico de lazer, a serviço da liberdade e da busca de excelência por parte de uma minoria privilegiada, marcou a pauta do lazer na Antiguidade. Historicamente, podemos associar o que hoje entendemos como lazer, a skolé grega, que sempre existiu e de forma diversa, enquanto a concepção de tempo livre é consequência do desenvolvimento industrial (Cuenca Cabeza, 2000). A partir deste período se instala o lazer burguês, como um tempo ganho do trabalho realizado. Entretanto, como nos adverte Lafargue (1991, p. 39),

os lazeres que o poeta pagão anunciou nunca vieram: a paixão cega, perversa e homicida do trabalho transforma a máquina libertadora em instrumentos de servidão dos homens livres: a sua produtividade empobrece-os.

Para este autor, a cegueira do operário pelo trabalho, na segunda metade do século XIX, período em que Lafarque escreve "O Direito a Preguiça”, fortalece a fortuna social, mas aumenta as misérias individuais e, ficando mais pobres, os operários tinham mais razão para continuar trabalhando e ser miseráveis. Quanto aos burgueses, Lafargue ressalta que, para desempenhar a condição de não produtor e superconsumidor, o burguês teve de violentar seus gostos modestos, "perder os seus hábitos de trabalho de dois séculos e entregar-se ao luxo desenfreado, às indigestões recheadas e às orgias sifilíticas" (Lafargue, 1991, p.43). Na análise da burguesia do século XIX, Lafargue ainda acrescenta que prostrada na preguiça absoluta e desmoralizada pelo gozo forçado, a burguesia se acomodou ao seu novo gênero de vida.

Este modelo de sociedade se estende pelo ocidente, principalmente a partir do século XIX, quando o trabalho para os ocidentais se converte no centro da vida, assumindo as escolas, a massificação e socialização das pessoas para o trabalho. O sistema de crença religiosa também contribuiu, por meio da ética protestante, para uma ética do trabalho (Gil, 1998). Quando o trabalho se desliga do resto das atividades do cotidiano das 
pessoas, e se assume a dicotomia entre o tempo de trabalho e o tempo livre, estamos ante, portanto, de um fenômeno exclusivo das sociedades modernas/industrializadas, que produzem assim a divisão temporal do cotidiano e a relação implícita entre trabalho, tempo livre e lazer. Neste contexto, uma das mais importantes transformações no início do período industrial até a atualidade têm sido a percepção e interpretação do tempo. Segundo Ruiz Olabuénaga (1994, p. 1921),

o tempo perdeu sua natureza sacra para se tornar profano. O tempo sacro é cíclico e transcorre em forma de círculos recorrente, em que o começo coincide com o fim e se apoia no mito do eterno retorno. (...) $\mathrm{O}$ tempo sacro não se vive sozinho, nem no privativo, mas em público e em comunidade.

Ainda com base em Ruiz Olabuénaga (1994), o tempo sacro é de todos e para todos, e é independente do sujeito individual. É um tempo para se viver em conjunto, não para ser fracionado nem privado. Já o tempo moderno, em palavras deste autor, é um tempo profano, que funciona pela soma de segmentos sucessivos, cuja principal característica é ser longitudinal. O tempo longitudinal é individual e privado, que passa a se constituir como um bem comercializável, variável, flexível e fracionado. A passagem do tempo cíclico ao linear implica, seguindo a Ruiz Olabuénaga (1994), uma troca do sol pelo relógio e das estações por um bloco de horários. O caráter longitudinal e privado do tempo na modernidade, entre outras causas, marcou as relações entre o tempo de trabalho, o tempo livre e o lazer. Se o importante no tempo moderno é a produção e o tempo livre não é produtivo, o mesmo só se justifica se está relacionado ao trabalho.

Cada sociedade tem sua construção do tempo. O tempo moderno é, antes de tudo, um tempo medido em horas, minutos e segundos. Dentro desta dinâmica do tempo, o tempo livre moderno é um tempo perdido e o trabalho é sinônimo de vida e fonte de riqueza. Como ressalta Russell (2002, 32), "o homem moderno acha que qualquer atividade deve ser exercida em prol de outras coisas, nunca da coisa mesma”. Para este autor, "não temos tempo mental para adquirir outros conhecimentos além daqueles que hão de nos ajudar pelas coisas que consideramos importantes” (Russell, 2002, 39). Com estes valores, não é de se estranhar que o protestantismo tenha suprimido os cultos aos santos, pois assim também suprimiria os dias de festas, que eram dedicados a eles, e que se converteriam em dias produtivos (Lafargue, 1991; Montaner, 1996; Russell, 2002). Neste sentido, o tempo da sociedade moderna/industrial, como tempo social, é considerado algo objetivo, medido e quantificado. O lazer, como perspectiva de vivência humana, nesta realidade, é acusado de não dar sentido à vida real, já que são práticas guiadas pelo princípio da natureza contra a cultura, de paixão contra a razão (Fortuna, 1995). 
A ansiedade de produção dos novos industriais no princípio do modelo capitalista conduziu ainda, a aplicação de condições severas e de autêntica exploração laboral aos operários. Conforme a classe trabalhadora ia tomando consciência de sua situação social e se agrupando em organizações, fundamentalmente com a criação dos sindicatos, iniciam-se os movimentos reivindicativos por melhores condições de trabalho. Os objetivos das lutas operárias eram basicamente a redução da jornada de trabalho e o aumento dos salários, que se converteram nas premissas imprescindíveis para se gozar o tempo livre (Montaner, 1996). Desta conjuntura se deriva as condições atuais de regulamentação coletiva do trabalho e, com ela, do tempo livre do trabalhador. Mas ainda com estes ganhos de redução da jornada de trabalho, justamente por se associar com a parte do prazer da vida, o lazer ainda é desvalorizado, pois lhe é atribuído uma conotação negativa, na escala de valores da sociedade moderna. O fato de ter tempo livre, portanto, não implicou necessariamente em viver o lazer (Elias, 1992; Leif, 1992; Cuenca Cabeza, 2000).

O tempo de lazer, que o identificamos dentro do tempo livre, é uma parte do tempo que está destinada as atividades de livre escolha, porque é agradável para quem a vivencia e não envolve remuneração. A materialização do lazer só se efetiva em uma verdadeira disponibilidade para si mesmo, que está relacionada na realização de algo distinto das ocupações profissionais, com ou sem os outros, e que quem o pratica se sente ele mesmo e pessoalmente motivado (Leif, 1992). Nesta concepção moderna de lazer, o tempo de lazer é um conjunto de manifestações que cumprem uma função complementar ao trabalho, sendo, portanto, vivências marginais dentro do contexto social. Entretanto, nas palavras de Elias (1992, p. 149), "as características especiais das atividades de lazer só podem ser compreendidas se forem consideradas, não apenas em relação ao trabalho profissional, mas, também, em relação às várias atividades de não lazer, no quadro do tempo livre”. Isto porque o lazer, que em seu início foi entendido como um fenômeno social limitado, em quanto ao número de pessoas que podiam desfrutá-lo e quanto a sua importância social, passa a ser entendido, a partir da consolidação das sociedades modernas e industriais, como um fenômeno de massa. "O desenvolvimento das sociedades contemporâneas, industrializadas, urbanizadas, foi criando as condições estruturais que conduziram a uma explosão do lazer e das atividades que o sustentam" (Del Pino Artacho et al., 2001, p.14).

Desde o desenvolvimento da Sociedade do Bem-estar, presenciamos mudanças em que a sociedade civil e outros vários setores organizados da sociedade, assumem cada vez mais protagonismo reivindicando o lazer, não mais só o tempo livre, como um direito de todos. O próprio Estado, na sua concretização de políticas públicas, tem reorientado 
seus planos de governo e intervenções, e as práticas de lazer são introduzidas para a população em geral. Na contemporaneidade, como consequência destas mudanças, o lazer é plural e, diferentes práticas, que antes estavam separadas em tempo de trabalho, tempo livre e lazer, hoje se integram e se misturam, criando estruturas próprias, com diferentes valores e finalidades. As vivências de lazer ganham significado, importância e qualidade, na medida em que se separa do mero passatempo e se incorpora nas vidas das pessoas, como um valor pessoal e, ao mesmo tempo, social e econômico. Para Cuenca Cabeza (2000, p.30), "há quem diga que o lazer tem ocupado o lugar que a religião teve no passado e, se se analisa os dados referidos ao tempo, parece que se passa algo assim: o aumento do tempo de lazer vem unido com a diminuição geral do tempo dedicado às práticas religiosas”.

Analisando o lazer numa perspectiva mais conceitual, atualmente os estudiosos do tema não coincidem em dizer o que podemos considerar como lazer. De fato, para uma definição contemporânea de lazer, temos que incorporar aspectos complexos da dimensão humana e, por consequência, das sociedades contemporâneas. O atual período de crises de paradigma, de incertezas e de contradições da realidade social moderna/pós-moderna contribui para este contexto atual do lazer. Entretanto, na diversidade interpretativa do fenômeno do lazer, consideramos o lazer como experiências subjetivas, materializadas em práticas físico-esportivas, turísticas, artísticas e recreativas que formam parte de uma estrutura social, vivenciada por um período de tempo, sem caráter obrigatório. É um tempo para si mesmo, com um grau relativamente elevado de eleição individual, dentro de um contexto social. Os indivíduos que destas práticas participam, manifestam suas emoções mais latentes, como um modo de ser e perceber a vida, dentro de um descontrole socialmente aprovado. Entretanto, pensar uma definição de lazer dentro do contexto contemporâneo, em que as sociedades se encontram num processo entre a modernidade e a pós-modernidade, é complexo e arriscado, já que sentimentos, vivências e realidades bem opostas estão presentes tanto nas práticas de lazer como de trabalho. Chegar ao cume de uma montanha, descer um rio com correnteza, assinar um novo contrato de trabalho, são vivências da vida cotidiana que estimulam sentimentos antagônicos como o medo, a insegurança, o prazer e a satisfação. São sentimentos inseparáveis, que geram um complexo processo no cotidiano das pessoas, envolvendo o mundo do lazer e do trabalho.

\section{Em busca de um novo entendimento do lazer}

O trabalho no contexto contemporâneo está relacionado não somente com o trabalho que se tem, mas, principalmente, com a qualidade do trabalho que se tem, dos 
sentimentos que se experimentam e da percepção e valorização que lhe damos. O lazer dentro deste contexto, já não apresenta fronteiras tão delimitadas com o trabalho. Uma pessoa pode se realizar e se satisfazer tanto nas atividades de lazer, como nas de não lazer. Ganha a percepção individual, embora esta se encontre interconectada com as questões e vivências socioculturais. O lazer e o trabalho, neste sentido, são compreendidos como conceitos construídos a partir de significados e vivências individuais, gerados em contextos coletivos, dentro de uma lógica de prazer e de realização pessoal.

Analisando a relação atual entre o trabalho e o lazer, os mesmos se estruturam a partir de duas perspectivas: uma que diferencia claramente o trabalho do lazer, dentro de uma visão mais moderna de sociedade; a outra que estabelece relação de identidade e interconexão entre o lazer e o trabalho, a qual a situamos dentro dos valores pósmodernos. Nesta segunda perspectiva está uma revalorização das vivências de lazer. Neste entendimento, o trabalho não vai desaparecer e tampouco vamos viver a civilização do lazer - na realidade, o desenvolvimento do lazer está trazendo outras formas de trabalho - mas o lazer vem ocupando um espaço na vida das pessoas, que ao longo da história só era vivenciado pelas elites. Sem perder sua importância, o que sim está perdendo o trabalho é seu caráter de exclusividade (De Masi, 2000; Cuenca Cabeza, 1999).

O trabalho contemporâneo é complexo, multidimensional e multifatorial, assim como são as sociedades pós-modernas. Esta complexidade no trabalho e na vida cotidiana cria uma forte interconexão entre trabalho e lazer. Segundo Cuenca Cabeza (2000), pode se dizer que em muitos trabalhos está mesmo se perdendo o conceito de jornada laboral, devido à imprecisão de fronteiras entre o tempo de trabalho e o tempo livre. Neste contexto, o trabalho ganha não apenas novos contornos, mas, especialmente, começa a mudar o significado e o valor que tinha em outras épocas. Como ressalta Valls (2000), o tempo contemporâneo é um contínuo, repleto de atividades diversas de trabalho e de lazer, sem transição, de maneira semelhante a como o era antes do processo de industrialização, mas por motivos radicalmente distintos. Os novos formatos de trabalho não só modificam e é modificado pelo tempo livre e de lazer, mas também pela forma como o tempo é estruturado no cotidiano presente.

Na concepção pós-moderna de trabalho, já assistimos várias pessoas a se realizarem com plenitude e com prazer no seu trabalho. O trabalho que exige criatividade, observação, reflexão e comunicação são os que mais proporcionam prazer, assimilando-se as vivências de lazer. Com estas novas características do trabalho se analisam também novas relações entre o desenvolvimento humano e a técnica, que é o 
mesmo que pensar na relação entre o lazer e o trabalho, pois "às formas de produção, distribuição e consumo de conteúdos criativos requer mudanças de modelos de negócios e formas de trabalhar, incluindo novas habilidades e infraestrutura" (Reis, 2012, p. 47). O lazer e o trabalho se apresentam assim, como dimensões criativas, com fortes influências nas dimensões da vida como um todo. Isto porque na perspectiva pós-moderna existe uma mútua influência entre o tempo profissional e o tempo que atualmente conceituamos como tempo livre e, por consequência, com o tempo de lazer. Como exemplifica De Masi (2000), um trabalhador da indústria preenchia seu tempo livre indo ao cinema, fazendo algo bem diferente do seu trabalho. Mas se um publicitário, um sociólogo, um psicólogo, um economista vai ao cinema, é difícil dizer onde começa a diversão e onde termina o trabalho, uma vez que sua atividade criativa dissipa qualquer barreira entre estudo, trabalho e tempo livre. Assim mesmo, esta inter-relação também deve ser compreendida no sentido inverso.

Nesta perspectiva, o tempo contemporâneo é um tempo de transição entre o trabalho material/mecânico, moderno e o trabalho/lazer imaterial, criativo, pós-moderno. $\mathrm{O}$ processo de trabalho/lazer criativo ainda encontra-se pouco disseminado na população, principalmente dos países em desenvolvimento ou subdesenvolvidos. Uma das causas da falta da disseminação desses novos valores do trabalho/lazer se pode encontrar no processo educativo, visto que a educação é um dos fatores essenciais para a construção de novos valores. Como já analisamos em outro lugar (Brasileiro, 2012), a educação é condição fundamental para o desenvolvimento humano, principalmente quando relacionada à mudança de paradigma do moderno para o pós-moderno. Entretanto, é necessário matizar que quando fazemos referência à educação, não nos referimos à educação instrumental, que valoriza o ensino da técnica para a sua reprodução, mas a educação que tem nos valores humanos o seu eixo central.

Assim como foi necessário o processo socializador do trabalho por meio da educação, também será necessário para o lazer, para que as pessoas estimulem sua criatividade, que será vivenciada em seus momentos de lazer/trabalho. Russell (2002), em 1935, considerava que as vivências de lazer são produtos da civilização e educação. Segundo este autor, "um homem que toda sua vida trabalhou longas horas irá se sentir entediado se ficar ocioso de repente" (Russell, 2002, p. 30). Isto porque o processo educativo da modernidade, só preparou as pessoas, a exceção da elite, para o trabalho. Russell ainda argumenta que, apesar da classe ociosa desfrutar de vantagens que despossuíam de qualquer fundamento de justiça, não se pode negar a sua contribuição para o que hoje chamamos de civilização, pois foi esta classe que cultivou a arte, descobriu a ciência, 
inventou a filosofia e aperfeiçoou as relações sociais. Para este autor, sem a classe ociosa, a humanidade nunca teria emergido da barbárie.

Entretanto, Russell ainda ressalta que estas pessoas que fizeram a diferença na classe ociosa eram minoria, pois a estas se opunham a milhares de proprietários rurais e comerciantes, que não pensavam além das suas vivências diárias. Na contemporaneidade, entretanto, é necessário pensar em processos educativos de qualidade para todos, que envolvam os valores criativos e de descoberta, com referência nos diversos coletivos. E é que as categorias tempo, espaço, competição, solidariedade, ecossistema, qualidade de trabalho, etc. estão se reestruturando e, neste contexto, as atividades com valores puramente econômicos estão cedendo espaço para valores mais hedonistas e de novos comunitarismos, e a educação tem muito a construir com estes novos valores.

O rompimento das fronteiras entre o lazer e o trabalho nos leva, portanto, a todas estas reflexões e nos faz pensar que as vivências e concepções do lazer estão gradativamente tornando-se um fator que tem mais em conta a qualidade da experiência para o indivíduo durante as atividades realizadas, que o tipo de atividade realizada. As vivências de lazer nas sociedades pós-modernas, assim mesmo, parecem estar mais determinadas por fatores subjetivos na realização das mesmas, que por fatores objetivos, que antes determinavam as vivências do lazer moderno. Isto não quer dizer que estamos em um processo de dissociação entre o sistema e as pessoas, uma dissociação do mundo coletivo para um mundo completamente da subjetividade. Tratase de vivências humanas e sociais, experimentadas a partir de novos contornos, e que favorecem ao aparecimento de novos tipos de comunitarismos e de individualismo.

Os conceitos tempo livre e lazer trazem consigo, portanto, valores e condutas predominantemente de valores modernos. As relações de dependência do lazer ao trabalho, ou melhor, das dimensões da vida ao mundo do trabalho, ainda são fruto de uma leitura e valores do mundo da sociedade moderna, que em sua gênese está baseada nos valores e crenças aceitadas pelo ideal burguês (Gaya, 1997). Como argumenta Lafargue (1991, 59), referindo-se ao século XIX, "é necessário defender o trabalho e não impô-lo”. Em pleno século XXI argumentamos que necessitamos defender o trabalho e o lazer, como dimensões da vida cotidiana, e não impô-los. Parafraseando Kumar (1997, p. 17), parece haver de fato alguma coisa nas experiências das sociedades modernas contemporâneas que, "de forma persistente, provoca não apenas 'o senso do fim', mas também de novos começos”. E são nestes novos começos que defendemos novas leituras para entender as relações entre lazer/tempo livre/trabalho. 


\section{Conclusão}

Na contemporaneidade, é dentro da lógica do moderno e pós-moderno que o lazer se move, em uma escala de valores que vai desde o lazer para a recuperação do cansaço ocasionado pelo trabalho, passando pelas manifestações consumistas, pelas vivências desenfreadas, até as vivências de desenvolvimento humano, com relativa autonomia em relação às pressões laborais, de mercado e sociais. Afirmar, portanto, que o lazer é um conceito que se concretiza dentro de um conjunto de práticas que estão inseridas na lógica do prazer, da realização pessoal e/ou um tempo liberado para si mesmo, que são vivências opostas ao trabalho ou forma parte de práticas sociais associadas ao consumo alienado é simplificar um conceito complexo e amplo, que não pode ser entendido com uma leitura superficial, como muitas vezes se realiza na contemporaneidade.

Pelas transformações econômicas e socioculturais vividas na atualidade e refletidas nas vivências de lazer, talvez ainda não estejamos em condições de dar uma interpretação moderna, para nossa mentalidade moderna, sobre este fenômeno social. Ao trata-se de um tempo com novas configurações e realidades novas, sua interpretação requer novas categorias e uma linguagem também nova, para as quais, ainda não possuímos um arcabouço teórico bem desenvolvido. Entretanto, podemos afirmar que se está produzindo profundas mudanças no mundo do trabalho, do tempo livre e do lazer. Mudanças estas que nos limitamos a reconhecer que algo começa a se revelar, rompendo barreiras e criando novos paradigmas desta relação. $\mathrm{O}$ fato de refletirmos sobre questões pouco convencionais como o lazer e o tempo livre, por exemplo, na construção de um diálogo entre o indivíduo e a sociedade, interagindo mutuamente no tempo e espaço de lazer, já nos encaminha para o surgimento de novos valores. Assim mesmo, novas leituras e perspectivas de lazer não representa uma harmonia e um consenso em torno a este conceito, isto porque a superação de perspectivas, sempre nos conduz a novas perspectivas ambivalentes e multidirecionais.

\section{Referências Bibliográficas}

BAUMANN, Z. \& TESTER, K. (2002): La ambivalencia de la modernidad y otras conversaciones. Original: Conversations with Zygmunt Bauman (2001). Tradução: Albert Roca Álvarez. Barcelona. Piadós.

BRASILEIRO, M. D. S. (2012): Desenvolvimento e turismo: para além do paradigma econômico. In: BRASILEIRO, M. D. S.; MEDINA, J. C. C.; CORIOLANO, L. N.: Turismo, cultura e desenvolvimento. Campina Grande. EDUEPB, p. 75-98.

CUENCA CABEZA, M. (2000): Ocio Humanista. Bilbao. Universidad de Deusto.

DE MASI, D. (1999): A emoção é a regra. Original: L'emozione e la regra (1989). Tradução: Elia Ferreira Edel. $4^{\mathrm{a}}$ ed. Rio de Janeiro. José Olympio Editorial. 
DE MASI, D. (2000): O futuro do trabalho. Original: Il futuro del lavoro (1999). Tradução: Yadyr A. Figueiredo. $4^{\mathrm{a}}$ ed. Rio de Janeiro. José Olympio Editorial.

DEL PINO ARTACHO, J.; DUASO AGUADO, A.; MARTÍNEZ, C. (2001): Prácticas de ocio, cambio cultural y nuevas tecnologías en la juventud española de fin de siglo. Madrid. Centro de Investigación Sociológica.

EAGLETON, T. (1998): As ilusões do pós-modernismo. Original: The Ilusions of Postmodernism (1996). Tradução: Elisabeth Barbosa. Rio de Janeiro. Jorge Zahar.

ELIAS, N. (1992): A busca da excitação. Original: The Quest for Excitement (1985). Tradução: Maria Manuela Almeida e Silva. Lisboa. Difusão Editorial.

FEATHERSTONE, M. (2000): Cultura de consumo y posmodernismo. Original: Consumer Culture and Postmodernism (1991). Tradução: Eduardo Sinnott. Buenos Aires. Amorrortu editores.

FORTUNA, C. (1995): Sociologia e práticas de lazer. IN: Revista Crítica de Ciências Sociais. No 43 , p. 5-10.

GAYA, A. (1997): Lazer e trabalho: os limites ideológicos de uma relação de subserviência. IN: COSTA, L. (editor): Meio Ambiente e desporto: uma perspectiva internacional. Porto. Universidade do Porto, p. 145-153.

GIL, F. (1998): El papel del ocio: entre la discriminación y la liberación. IN: GIL, F. (coord.): Para comprender el ocio. Navarra. Ed. Verbo Divino, p. 33-51.

LAFARQUE, P. (1991): O direito a preguiça. Original: Le Droit a la Paresse (1883). Tradução: Antônio José Massano. $3^{\mathrm{a}}$ ed. Lisboa. Ed. Teorema.

LASH, S. (1997): La reflexividad y sus dobles: estructura, estética, comunidad. IN: BECK, U., GIDDENS, A. e LASH, S.: Modernización reflexiva - política, tradición y estética en el orden social moderno. Original: Reflexive, Modernization, Politics, Tradition and Aesthetics (1994). Tradução: Jesus Alborés. Madrid. Alianza.

LEIF; J. (1992): Tiempo libre y tiempo para uno mismo. Madrid. Narcea Ed.

LÓPEZ DE LA VIEJA, M. T. (1998): Ocio y punto de vista moral.IN: GIL, Fernando (coord.): Para comprender el ocio. Navarra. Ed. Verbo Divino, p. 13-31.

MARTÍN HORCAJO, M. (2003): El deporte en las sociedades postmodernas. IN: MOSQUERA, M. J. e GAMBAU, V.: Deporte y Postmodernidad: VII Congreso de la AEISAD. Madrid. Esteban Sanz, p. 25-45.

MAZÓN, T. (2001): Sociología del Turismo. Madrid. Ed. Centro de Estudios Ramón Areces.

MONTANER, J. (1996): Psicosociología del turismo. Madrid. Síntesis.

PUIG ROVIRA, J. \& TRILLA, J. (1996): La pedagogía del ocio. Barcelona. Editorial Laertes.

RAGO, M. (2000): O cassino americano, ou reflexiones sobre o lazer em tempos pósmodernos. IN: BRUHNS, H. T. e GUTIERREZ, L. G. (orgs): O corpo e o lúdico: ciclo de debates lazer e motricidade. Campinas. FEF- UNICAMP, p. 05-18.

REIS, A. C. F. (2012): Cidades Criativas. São Paulo. SESI-SP Editora. 
RUIZ OLABUENAGA, J. I. (1994): Ocio y estilos de vida. In: M. JUÁREZ (ed.): $V$ Informe sociológico sobre la situación social en España. Madrid. Fundación Foessa.

RUSSELL, B. (2002): O elogio ao ócio. Original: In Praise of Idleness (1935). Tradução: Pedro Jorgensen Júnior. $4^{\mathrm{a}}$ ed. Rio de Janeiro. Sextante.

SAN MARTÍN, J. E. (1997): Psicosociología del ocio y el turismo. Granada. ALJIBE.

TOURAINE, A. (2009): Crítica da Modernidade. Original: Critique de la modernité (1990). Tradução: Elia Ferreira Edel. $9^{\text {a }}$ ed. Petrópolis. Vozes.

VALLS, J-F. (2000): Gestión de empresas de turismo y ocio. Barcelona. ESADE.

VEBLEN, T. (2004): Teoría de la clase ociosa. Original: The Theory of the Leisure Class (1899). Tradução: Carlos Mellizo. Madrid. Alianza editorial.

Dilma Brasileiro tem uma Graduação em Educação Física pela Universidade Federal da Paraíba (UFPB)/Brasil. Tem um Mestrado em Ciências do Desporto de Recreação e Lazer pela Universidade do Porto/Portugal. Tem um Doutorado Europeu em Sociologia, pela Faculdade de Ciências Políticas e Sociologia (Universidade de Granada/Espanha), com estágio na Universidade de Montpellier 1/França. Fez um Pósdoutorado pelo Departamento de Sociologia e Direito da Economia (Universidade de Bolonha/Itália). É professora titular da UFPB e atua nos cursos de Educação Física e Turismo e no Programa de Pós-graduação em Desenvolvimento Regional (UEPBUFCG). É líder do Laboratório de Estudos em Lazer, Esporte, Turismo e Sociedade (LAESTUS/UFPB/CNPQ).

dsbrasileiro@gmail.com 